\title{
Minimum Structural Requirements for Fungicidal Evaluation of $N$-Phenyl- $O$-phenylthionocarbamates against the Capsicum Phytophthora Blight (Phyophthora capsici) Based on the 3D-QSARs
}

\author{
Min-Gyu Soung, Seok-Chan Jang, and Nack-Do Sung* \\ Department of Applied Biology and Chemistry, College of Agriculture and Life Science, Chungnam National University, \\ Daejeon 305-764, Korea. ${ }^{*}$ E-mail: ndsung15@hanmail.net \\ Received March 23, 2010, Accepted September 15, 2010
}

\begin{abstract}
In this study, the 3D-QSARs (three-dimensional quantitative structure-activity relationships: CoMFA and CoMSIA) between structural changes of $N$-phenyl- $O$-phenylthionocarbamate analogues (1-30) and their fungicidal activities against the capsicum phytophthora (Phyophthora capsici) fungi were analyzed, then considered quantitatively in terms of minimum structural requirements for fungicidal evaluation. The statistical qualities $\left(\mathrm{r}_{\mathrm{cv} .}^{2}=0.510\right.$ and $\mathrm{r}_{\text {ncv. }}^{2}=$ 0.948) of the optimal CoMFA 1 model are improved over the other models in the conditions of field combinations, and the two alignments. In the optimal CoMFA 1 model, relative contribution percentages of the CoMFA field were: steric field, 52.3\%; electrostatic field, 37.8\%; hydrophobic field, 9.9\%. Results were similar for the CoMFA 2 model. Therefore, the steric field of the analogues had the highest contribution ratio for fungicidal activity. Specifically, with the contour map of steric fields, the fungicidal activity increased when bulky steric Y-substituents were introduced to the meta-position on the $\mathrm{N}$-phenyl ring and small steric $\mathrm{Y}$-subsituents were introduced to its para-position.
\end{abstract}

Key Words: CoMFA model, 3D-QSARs, Fungicidal activity, $N$-Phenyl-O-phenylthionocarbamates, Phytophthora capsici.

\section{Introduction}

Carbamate family compounds concentrate selectively on the objects of prevention and are easily decomposed by microbes. ${ }^{1}$ This explains the practical efficacy of many carbamate family agrochemicals such as insecticides, disinfectants and herbicides. $^{2}$ Carbamate compounds, in particular, work actively against bacteria which contain cellulose in their cell walls, but not against bacteria which contain chitinous. They quickly seep into plants through their roots, so they are very effective against fungi transmissible by soil, like Phytophthora and Pyrium.

On the other hand, the capsicum phytophthora (Phyophthora capsici, hereinafter referred to as PC) blight damages not only red peppers but also crops such as tomatoes and calabash. ${ }^{3}$ This pathogen is soil permeable, and produces enough spores to spread over large areas of cultivated land. It can exist in the crop itself and within the land under cultivation. Once the pathogen becomes resistant to once-effective agrochemicals, it becomes hard to control ${ }^{4}$. However, it seems that disinfectants from the phenylamide family and compounds of the metalaxy family may inhibit the permeability of the pathogen. ${ }^{5,6}$ Because of the abuse of agrochemicals, the resistant pathogen of Phytophthora has appeared quickly and spread at a fast rate. For this reason, it now causes great damage to crops of tomatoes, calabash, red peppers, and etc. This situation is worsening. With the increase in the number of pathogen-resistant species, the development of new pesticides has become keenly necessary. Areas that have been evaluated and studied by thionocarbamate analogues so far have included physical organic chemistry; ${ }^{7}$ synthesis technology; ${ }^{8}$ proteomic analysis of the antimetastatic effect; ${ }^{9}$ and QSAR analyses of cell cytotoxicity, ${ }^{10}$ fungicidal activity, ${ }^{11}$ and insecticidal activity. ${ }^{12}$
To develop new pesticides which, based on the results of previous studies, ${ }^{13}$ can effectively prevent $\mathrm{PC}$ fungi, the goal has been to synthesize a series of $N$-phenyl- $O$-phenylthionocarbamate analogues (hereafter referred to as PTCs). We analyzed 3D-QSARs (CoMFA, comparative molecular field analysis and CoMSIA, comparative molecular similarity indice analysis ${ }^{14}$ ) related to fungicidal activity, concentrating on the changes of substituents ( $\mathrm{X}$ and $\mathrm{Y}$ ), and finally examined structural characteristics of compounds with high fungicidal activity.

\section{Materials and Methods}

Molecular modeling. The fungicidal activities of PTCs (1-28) against the PC fungi have been determined through previous studies. ${ }^{15}$ 3D-QSAR models were derived from the training set $(\mathrm{n}=22)$, and six compounds were excluded from the training set to serve as the test set $(n=6)$ in order to evaluate the predictive accuracy of the present optimal model. The strength of fungicidal activity against the PC fungi depends on the changes in the substituents (X and Y) of PTCs. To produce 3D-QSAR (CoMFA and CoMSIA) models which can effectively explain this relation, the Sybyl program (Ver. 8.0) was used ${ }^{16}$ under the same guided conditions (minimization of conformers: cycle, 10 and temp, $200-1,000{ }^{\circ} \mathrm{C}$; alignments: $\mathrm{AF}$ (atom based fit) and FF (field fit); number of components: 1-5; CoMFA field: standard, indicator and H-bond; and CoMSIA field: electrostatic, steric, hydrophobic (clogP), H-bond acceptor, and H-bond donor) and following the same procedures. ${ }^{17}$ Each molecule in the three-dimensional cubic lattice space was arranged by grid intervals of 1.0 to $3.0 \AA$, and $\mathrm{sp}^{3}$ hybridized carbon atoms, with $\mathrm{a}+1.0$ charge, were the probe atoms, arranged in regular intervals. In order to explain dispersions among molecules and 
electrostatic fields by Coulombic potential between probe atoms and the other parts of molecules, we calculated the energy of Van der Waals potential using Lennard-Jones potential. ${ }^{18}$ In addition, we included clogP values as an additional descriptor in order to consider the hydrophobic field. The four 3D-QSAR models derived under the combination of alignments (atom based fit: AF and field fit: FF), grid $\AA$ ( $1-3 ; 0.50 \AA$ interval), major components (3-5), and characteristic 3D-QSAR fields showed the best statistical qualities.

PLS analyses. In the three-dimensional space, the structures of PTCs are aligned with two ways: first, by AF and, second, by FF. ${ }^{19}$ Using the PLS (partial least-square) method, ${ }^{20}$ we calculated a correlation between descriptors which concerned 3D structural characteristics of aligned compounds and biological activity, so that we were able to search for a 3D-QSAR model with high correlativity. Through the LOO (Leave-One-Out) cross-validated process and $\mathrm{q}^{2}$ (or $\mathrm{r}_{\mathrm{cv}}^{2}$ ), the number of components was found, thus helping in deciding an optimal number of components. Based on this non-cross-validation process, we determined the $\mathrm{r}^{2}$ ncv. value under the condition of scaling (CoMFA standard and column filtering: $2.0 \mathrm{kcal} / \mathrm{mol}^{21}$ ). In the cases of $\mathrm{r}_{\text {ncv. }}^{2} \geq 0.90$ and $\mathrm{q}^{2} \geq 0.5$, we can say that the model has a reasonable level of predictability. The properties of the CoMFA and CoMSIA fields were expressed as contour maps in three-dimensional space. Futhermore, the favor:disfavor ratio (of the CoMFA and CoMSIA fields was 80\%:20\%.

\section{Results and Discussion}

Fungicidal activity. The fungicidal activity values $\left(O b s . p I_{50}\right)$ which, according to changes of substituents (Y) of PTCs, were effective against the PC fungi are summarized in Tables 1 and 4. The scope of fungicidal activities that were observed was between 3.55 and $5.35\left(\mathrm{Obs} \cdot \mathrm{pI}_{50}=3.55\right.$ to 5.35$)$ and these were above the average values $\left(\mathrm{pI}_{50}=3.18\right.$ to 4.15 ; Ave. $\mathrm{pI}_{50}=3.64$ ) reached in a previous study. ${ }^{13}$ Compound $27\left(\mathrm{X}=\mathrm{NO}_{2}, \mathrm{Y}=3\right.$ $\left.\mathrm{NHCOCH}_{3}\right)$ had the lowest fungicidal activity value $\left(\mathrm{Obs} \cdot \mathrm{pI}_{50}=\right.$ 3.55) and compound $\mathbf{1 7}\left(\mathrm{X}=\mathrm{NO}_{2}, \mathrm{Y}=3-\mathrm{NO}_{3}\right)$ had the highest $\left(\right.$ Obs.pI $\left.I_{50}=5.35\right)$. Also performed were CoMFA and CoMSIA analyses for understanding the relations (3D-QSAR) between the changes of X and Y substituents of PTCs (1-28) and fungicidal activity against the $\mathrm{PC}$ fungi.

3D-QSAR models. Table 1 offers a summary of fungicidal activity values $\left(O b s . \mathrm{pI}_{50}\right)$ that were observed in the training set $\left(\mathrm{n}=22\right.$ ), values (Pred.pI $\left.\mathrm{f}_{50}\right)$ predicted by the CoMFA 1 and CoMFA 2 models which showed the ideal values under different kinds of alignment conditions, and the differences $\left(\Delta \mathrm{pI}_{50}\right)$ between these two values. Summarized in Table 2 are the results of a PLS analysis of four models which represented the highest statistical value among models which were derived by a component number (3), a grid (1.0 to $1.5 \AA$ ), and alignment conditions (AF and FF). CoMFA models were more significant than CoMSIA models and there were no remarkable differences in the statistical values between the CoMFA 1 and the CoMFA 2 models. The optimal model was the CoMFA 1 model (correlative: $r_{n c v}^{2}=0.960$ and predictive: $r_{\mathrm{cv}}^{2}=0.633$ ). Figure 1 explains relationships between observed values $\left(O b s . \mathrm{pI}_{50}\right)$ of training set compounds and predicted values (Pred.pI $\left.\mathrm{I}_{50}\right)$, through
Table 1. Observed fungicidal activity $\left(O b s . \mathrm{pI}_{50}\right)$ of PTCs, predicted activity (Pred.pI $\left.I_{50}\right)$ by the CoMFA models, and difference $\left(\Delta \mathrm{pI}_{50}\right)$ of two the activity for training set

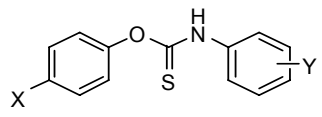

\begin{tabular}{|c|c|c|c|c|c|c|c|}
\hline \multirow{2}{*}{ No. } & \multicolumn{2}{|c|}{ Substituents } & \multirow{2}{*}{ Obs.pI $I_{50}$} & \multicolumn{2}{|c|}{ CoMFA $1^{a}$} & \multicolumn{2}{|c|}{ CoMFA 2} \\
\hline & $X$ & Y & & Pred. $^{b}$ & $\overline{\Delta \mathrm{pI}_{50}{ }^{c}}$ & Pred. $^{b}$ & $\Delta \mathrm{pI}_{50}{ }^{\mathrm{c}}$ \\
\hline 1 & $\mathrm{CH}_{3} \mathrm{O}$ & $3-\mathrm{NH}_{2}$ & 4.11 & 3.94 & 0.17 & 4.00 & 0.11 \\
\hline 3 & $\mathrm{CH}_{3} \mathrm{O}$ & $3-\mathrm{NO}_{2}$ & 4.83 & 4.85 & -0.02 & 4.84 & -0.01 \\
\hline 4 & $\mathrm{CH}_{3} \mathrm{O}$ & $3-\mathrm{CONH}_{2}$ & 4.53 & 4.59 & -0.06 & 4.57 & -0.04 \\
\hline 7 & $\mathrm{CH}_{3} \mathrm{O}$ & $4-\mathrm{COCH}_{3}$ & 4.84 & 4.88 & -0.04 & 4.87 & -0.03 \\
\hline 8 & $\mathrm{CH}_{3} \mathrm{O}$ & 4- $\mathrm{CO}_{2} \mathrm{CH}_{3}$ & 3.64 & 3.68 & -0.04 & 3.65 & -0.01 \\
\hline 9 & $\mathrm{CH}_{3} \mathrm{O}$ & 4- $\mathrm{CO}_{2} \mathrm{CH}_{2} \mathrm{CH}_{3}$ & 3.71 & 3.65 & 0.06 & 3.65 & 0.06 \\
\hline 10 & $\mathrm{CH}_{3} \mathrm{O}$ & $4-\mathrm{SCH}_{3}$ & 4.20 & 4.18 & 0.02 & 4.17 & 0.03 \\
\hline 11 & $\mathrm{CH}_{3} \mathrm{O}$ & 4-COOH & 5.2 & 5.36 & -0.09 & 5.33 & -0.06 \\
\hline 12 & $\mathrm{CH}_{3} \mathrm{O}$ & $2-\mathrm{F}$ & 4.35 & 4.37 & -0.02 & 4.34 & 0.01 \\
\hline 13 & $\mathrm{CH}_{3} \mathrm{O}$ & $2-\mathrm{Cl}$ & 4.4 & 4.42 & 0.04 & 4.41 & 0.05 \\
\hline 15 & $\mathrm{NO}_{2}$ & $\mathrm{H}$ & 4 & 4.45 & -0.13 & 4.49 & -0.17 \\
\hline 17 & $\mathrm{NO}_{2}$ & $3-\mathrm{NO}_{2}$ & 5.3 & 5.08 & 0.27 & 5.06 & 0.29 \\
\hline 18 & $\mathrm{NO}_{2}$ & $3-\mathrm{NHCOCH}_{3}$ & 3.78 & 3.85 & -0.07 & 3.86 & -0.08 \\
\hline 19 & $\mathrm{NO}_{2}$ & $3-\mathrm{Cl}$ & 4.91 & 4.76 & 0.15 & 4.75 & 0.16 \\
\hline 20 & $\mathrm{NO}_{2}$ & $4-\mathrm{Br}$ & 4.54 & 4.64 & -0.10 & 4.65 & -0.1 \\
\hline 21 & $\mathrm{NO}_{2}$ & $4-\mathrm{NH}_{2}$ & 4.0 & 4.11 & -0.04 & 4.10 & -0.03 \\
\hline 22 & $\mathrm{NO}_{2}$ & $4-\mathrm{NO}_{2}$ & 4.85 & 4.86 & -0.01 & 4.88 & -0.03 \\
\hline 23 & $\mathrm{NO}_{2}$ & $4-\mathrm{SCH}_{3}$ & 4.32 & 4.23 & 0.09 & 4.26 & 0.06 \\
\hline 24 & $\mathrm{NO}_{2}$ & $4-\mathrm{CH}_{3} \mathrm{O}$ & 4.02 & 4.07 & -0.05 & 4.06 & -0.04 \\
\hline 25 & $\mathrm{NO}_{2}$ & $4-\mathrm{Cl}$ & 4.54 & 4.63 & -0.09 & 4.65 & -0.11 \\
\hline 26 & $\mathrm{NO}_{2}$ & 4-NHCOCH 3 & 3.55 & 3.54 & 0.01 & 3.50 & 0.05 \\
\hline 27 & $\mathrm{NO}_{2}$ & $4-\mathrm{CH}_{3}$ & 4.40 & 4.46 & -0.06 & 4.49 & -0.09 \\
\hline
\end{tabular}

${ }^{a}$ Optimal model; ${ }^{b}$ predicted values by the models; ${ }^{c}$ different between observed and predicted value.

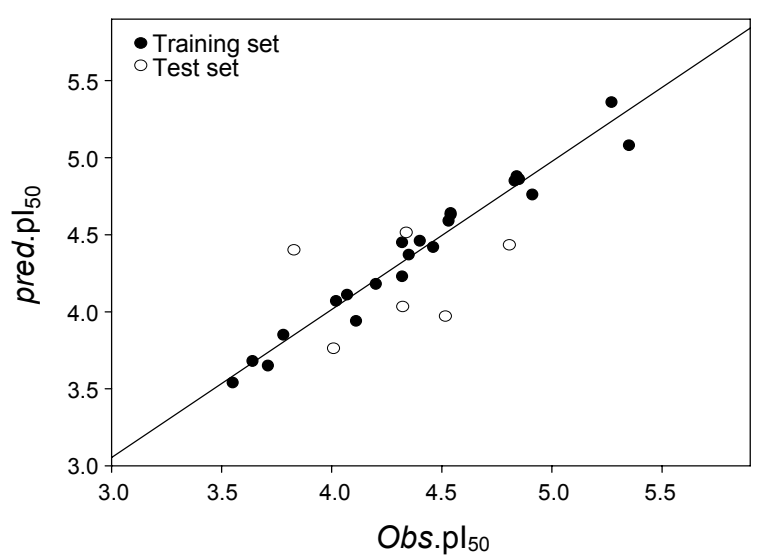

Figure 1. Observed insecticidal activity $\left(O b s . p I_{50}\right)$ against $\mathrm{PC}$ fungi and predicted inhibition activity (pred.pI $\mathrm{I}_{50}$ ) by the optimized CoMFA 1 model. (For training set: Pred.pI $5_{50}=0.961$ Obs.pI $I_{50}+0.171 \mathrm{n}=22$, $\left.\mathrm{s}=0.098, \mathrm{~F}=487.360, \mathrm{r}^{2}=0.961 \& \mathrm{q}^{2}=0.940\right)$.

the optimal CoMFA 1 model. This linear relation (for the training set: Pred. $\mathrm{pI}_{50}=0.961 O b s . \mathrm{pI}_{50}+0.171 \mathrm{n}=22, \mathrm{~s}=0.098, \mathrm{~F}=$ $487.360, r^{2}=0.961$, and $\mathrm{q}^{2}=0.940$ ) shows a good correlation with the CoMFA 1 model, but test set compounds were not quite linear.

In addition, Table 3 represents contribution ratios (accord- 
Table 2. Summary of the statistical parameters of 3D-QSAR models with two alignments

\begin{tabular}{cccccccc}
\hline \multirow{2}{*}{ Model No. } & \multirow{2}{*}{ Alignments } & \multicolumn{5}{c}{ PLS Analyses } \\
\cline { 3 - 8 } & & Grid $(\AA)$ & Component & r $^{2}{ }_{\text {cv. }}{ }^{a}$ & $\mathrm{r}^{2}{ }_{\text {ncv. }}{ }^{b}$ & SEvv. $^{c}$ & $\mathrm{~F}$ \\
\hline CoMFA 1 $^{d}$ & $\mathrm{AF}$ & 1.5 & 3 & 0.633 & 0.960 & 0.107 & 142.315 \\
CoMFA 2 & $\mathrm{FF}$ & 1.5 & 3 & 0.610 & 0.958 & 0.109 & 138.348 \\
CoMSIA 1 & $\mathrm{AF}(\alpha=0.4)$ & 1.0 & 3 & 0.753 & 0.931 & 0.140 & 80.493 \\
CoMSIA 2 & $\mathrm{FF}(\alpha=0.3)$ & 1.0 & 3 & 0.745 & 0.927 & 0.144 & 76.107 \\
\hline
\end{tabular}

Notes: F: fraction of explained versus unexplained variance; attenuation factor: $\alpha ;{ }^{a}$ cross-validated $\mathrm{r}^{2} ;{ }^{b}$ non-cross-validated $\mathrm{r}^{2} ;{ }^{c}$ standard error estimate; ${ }^{d}$ optimal model.

Table 3. Summary of field contribution, Ave. and PRESS of 3D-QSAR models

\begin{tabular}{|c|c|c|c|c|c|c|c|c|c|}
\hline \multirow{2}{*}{ Model No. } & \multicolumn{5}{|c|}{ Field contribution ratio $(\%)$} & \multicolumn{4}{|c|}{ Training set } \\
\hline & $\mathrm{S}$ & $\mathrm{E}$ & Hy & HD & HA & Ave. & PRESS & Ave. & PRESS \\
\hline CoMFA $1^{a}$ & 52.3 & 37.8 & 9.9 & - & - & 0.07 & 0.173 & 0.39 & 1.049 \\
\hline CoMFA 2 & 53.1 & 36.7 & 10.1 & - & - & 0.07 & 0.200 & 0.43 & 1.283 \\
\hline CoMSIA 1 & 13.2 & 40.6 & 11.5 & 36.0 & 18.7 & 0.10 & 0.348 & 0.47 & 1.738 \\
\hline CoMSIA 2 & 11.5 & 36.4 & 13.6 & 20.1 & 18.4 & 0.10 & 0.365 & 0.48 & 1.853 \\
\hline
\end{tabular}

Notes: S: steric; E: electrostatic; Hy: hydrophobic; HD: H-bond donor field; HA: H-bond accept field; Ave.: average residual; PRESS: predictive residual sum of squares; ${ }^{a}$ optimal model.

Table 4. Observed fungicidal activity $\left(O b s . \mathrm{pI}_{50}\right)$ of PTCs, predicted activity $\left(\right.$ Pred.pI $\left.\mathrm{I}_{50}\right)$ by the CoMFA models, and difference $\left(\Delta \mathrm{pI}_{50}\right)$ of activities for test set

\begin{tabular}{|c|c|c|c|c|c|c|c|}
\hline \multirow{2}{*}{ No. } & \multicolumn{2}{|c|}{ Substituents } & \multirow{2}{*}{ Obs.pI $\mathrm{I}_{50}$} & \multicolumn{2}{|c|}{ CoMFA $1^{a}$} & \multicolumn{2}{|c|}{ CoMFA 2} \\
\hline & $X$ & Y & & Pred. $^{b}$ & $\Delta \mathrm{pI}_{50}{ }^{c}$ & Pred. $^{b}$ & $\Delta \mathrm{pI}_{50}{ }^{c}$ \\
\hline 2 & $\mathrm{CH}_{3} \mathrm{O}$ & $3-\mathrm{NHCOCH}_{3}$ & 4.52 & 3.91 & 0.61 & 3.80 & 0.72 \\
\hline 5 & $\mathrm{CH}_{3} \mathrm{O}$ & $4-\mathrm{OH}$ & 4.83 & 4.38 & 0.45 & 4.39 & 0.44 \\
\hline 6 & $\mathrm{CH}_{3} \mathrm{O}$ & $4-\mathrm{NH}_{2}$ & 4.30 & 4.00 & 0.30 & 4.00 & 0.03 \\
\hline 14 & $\mathrm{CH}_{3} \mathrm{O}$ & $2-\mathrm{CF}_{3}$ & 3.82 & 4.41 & -0.59 & 4.43 & -0.61 \\
\hline 16 & $\mathrm{NO}_{2}$ & $3-F$ & 4.34 & 4.54 & -0.20 & 4.54 & -0.20 \\
\hline 28 & $\mathrm{NO}_{2}$ & $4-\mathrm{CO}_{2} \mathrm{CH}_{2} \mathrm{CH}_{3}$ & 4.04 & 3.73 & 0.31 & 3.76 & 0.28 \\
\hline
\end{tabular}

${ }^{a}$ Optimal model; ${ }^{b}$ predicted values by models; ${ }^{c}$ different between observed and predicted value.

ing to percentage) for CoMFA and CoMSIA fields of the four models derived from each condition. In the optimal CoMFA 1 model, the relative contribution percentages of the CoMFA field were: steric field, 52.3\%; electrostatic field, 37.8\%; and hydrophobic field, 9.9\%. The CoMFA 2 model showed similar results. The errors (Ave. and PRESS) of the training set compounds and those of the test set $(n=6)$ were calculated and summarized in Table 3 . In the case of the optimal CoMFA 1 model, the average residual (Ave.) of the training set was acceptable (Ave. $=0.07$ and PRESS $=0.173$ ) and the test set error resulted in low predictability, as anticipated in Figure 1. This is because compounds lacking linearity were test set compounds discovered through the relation between observed values and predicted values, for the purpose of creating a model with a high level of correlation. Activity values predicted for the training set and test set compounds, determined through the CoMFA 1 and CoMFA 2 models, and the differences $\left(\Delta \mathrm{pI}_{50}\right)$, were recorded Table 4.

3D-QSAR contour maps. For the purpose of analyzing the amount of contributions made by characteristic fields related

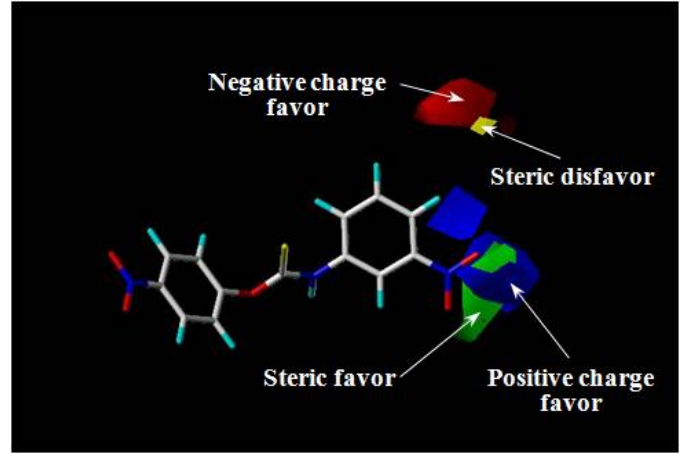

Figure 2. Contour map for steric and electrostatic field of the optimal CoMFA 1 model. The most active compound (17) is shown in capped sticks.

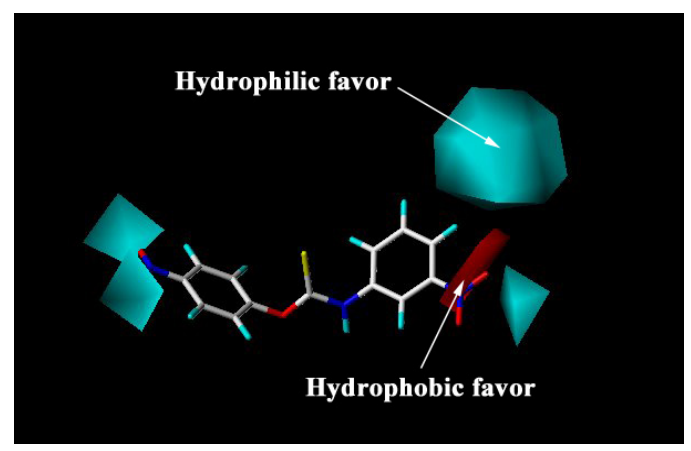

Figure 3. CoMFA-HINT contour map for hydrophobic field of the optimal CoMFA 1 model. The most active compound (17) is shown in capped sticks.

to the optimal CoMFA 1 model, contour maps of the steric field and the electrostatic field are provided in Fig. 2. In the contour map of steric fields, the fungicidal activity was seen to increase 
when bulky steric substituents (green) were introduced to the meta-position on the $N$-phenyl ring and small steric substituents (yellow) were introduced to its para-position. In the contour map of electrostatic fields, the fungicidal activity was seen to increase when positive charges (blue) of the substituents appeared in the meta- and para-positions on the $N$-phenyl ring and negative charges of Y-substituents appeared between para- and meta-positions. On the other hand, Fig. 3 shows the HINT map of hydrophobic fields. ${ }^{22}$ When hydrophilic favor substituents in the form of Y-substituents on the $N$-phenyl ring were located in the meta- $\left(\mathrm{C}_{3}\right.$ atom) and para-positions $\left(\mathrm{C}_{4}\right.$ and $\mathrm{C}_{5}$ atom), and hyprophilic favor substituents in the form of X-substituents of the $O$-phenyl group were located in the para-position, the fungicidal activity increased. The parts favoring hydrophobic conditions occupied larger regions in the para-position than in the meta-position. In conclusion, graphic analysis results of 3DQSAR contour maps explain the relations between quantitative structures of PTCs and the fungicidal activities. Further, they can be used effectively to design and select molecules with improved activities.

Acknowledgments. This work was supported by a National Research Foundation (NRF) grant (No. 2010-0062913) funded by the Korean Government (MEST).

\section{References}

1. Hutson, D. H.; Roberts, T. R. Insecticides, In Progress in Pesticide Biochemistry and Toxicology; Wiley: Chichester, 1987; Vol. 5.

2. Cremlyn, R. J. In Agrochemicals Preparation and Mode of Action Synthetic Insecticides II, Organophosphorus and Carbamate Compounds; John Wiley \& Sons: UK, 1991; Ch. 6.

3. Hwang, B. K.; Kim, C. H. Plant. Dis. 1995, 79, 221.

4. (a) Parra, G.; Ristaino, J. B. Plant. Dis. 2001, 85, 1069. (b) Georgakopoulos, D. G.; Fiddaman, P.; Leifert, C.; Malathrakis, N. E. J. Appl. Mircobiol. 2002, 92, 1078.

5. Cvitanich, C.; Judelson, H. S. Curr. Genet. 2003, 42, 228.
6. Lee, H. B.; Kim, Y.; Kim, J. C.; Choi, G. J.; Park, S. H.; Kim, C. J.; Jung, H. S. J. App. Micro. 2005, 99, 836.

7. (a) Park, S. Y.; Oh, H. K. Bull. Korean Chem. Soc. 2009, $30,749$. (b) Silva, D.; Norberto, F.; Santos, S.; Herves, P. J. Phy. Org. Chem. 2009, 22, 221.

8. (a) Liu, D. Y.; Niu, J. B.; Zhao, L. N. Jangxi Shifan daxue Xuebao, Ziran kexueban 2007, 31, 566. (b) Min, K. J. Kor. J. Env. Hlth. Soc. 1991, 17, 104.

9. Choi, S. L.; Choi, Y. S.; Kim, Y. K.; Sung, N. D.; Kho, C. W.; Park, B. C.; Kim, E. M.; Lee, J. H.; Kim, K. M.; Kim, M. Y.; Myung, P. K. Arch. Pharm. Res. 2006, 29, 224.

10. Sung, N. D.; Myung, P. K.; Seong, M. G.; Yu, S. J.; Choi, S. L. Agri. Chem. Biotech. 2003, 46, 137.

11. Albores-Velasco, M.; Thorne, J.; Wain, R. L. J. Agri. Food Chem. 1995, 43, 2260.

12. Kochansky, J.; Cohen, C. F. J. Agri. Entomol. 1990, 7, 293.

13. (a) Martha, A. V.; John, T.; Ralph, L. W. J. Agric. Food Chem. 1995, 43, 2260. (b) Sung, N. D.; Soung, M. G.; You, J. W.; Jang, S. C. Korean J. Pesticide Sci. 2006, 10, 157.

14. Kubiny, H. 3D-QSAR in Drug Design: Theory, Methods and Applications; ESCOM: Leiden, 1993.

15. Jang, S. C. Msc. Thesis, Graduate School of Chungnam National University, Korea, 2007.

16. Tripos, S. Molecular modeling and QSAR software on CD-Rom (Ver.8.0); Tripos Associates, Inc., 1699 S. Hanley Road, Suit 303, St. Louis, MO. 63144-2913, U.S.A.

17. (a) Soung, M. G.; Lee, Y. J.; Sung, N. D. Bull. Korean Chem. Soc. 2009, 30, 613. (b) Soung, M. G.; Kil, M. J.; Sung, N. D. Bull. Korean Chem. Soc. 2009, 30, 2749.

18. Clark, M.; Crammer, R. D., III.; Van Opdenbosh, N. J. Comput. Chem. 1989, 10, 982.

19. Murthy, V. S.; Kulkarni, V. M. Bioorg. Med. Chem. 2002, 10, 2267.

20. Dunn, W. J.; Wold, S.; Edlund, U.; Hellberg, S.; Gasteiger, J. Quant. Struct. Act. Relat. Chem. Bio. 1984, 3, 31.

21. Crammer, R. D., III.; Bunce, J. D.; Patterson, D. E. Quant. Struct. Act. Relat. 1998, 7, 18.

22. Kellogg, G. E.; Semus, S. F.; Abraham, D. J. J. Comput.-Aided Mol. Des. 1991, 5, 545.

23. Kang, K. Y.; Park, K. H.; Kang, J. K.; Leoniden, T.; Yang, D. H. $\mathrm{N}$-2-Chloro-4-nitrophenylbenzenesulfonamide Derivatives Compounds Having Antifungal Activities against Phytopathogens and Method for Using Thereof. PA. KR 10-0538460. 2005. 